\title{
Towards messages that matter: Understanding and addressing HIV and SRH risks among married young people in India
}

Armin Jamshedji-Neogi

Renu Kapoor

Jayashree Kumar

Ashwini Bhalerao Gandhi

Lakshmi Murthy

See next page for additional authors

Follow this and additional works at: https://knowledgecommons.popcouncil.org/departments_sbsr-pgy

Part of the Demography, Population, and Ecology Commons, Family, Life Course, and Society Commons, International Public Health Commons, Maternal and Child Health Commons, and the Medicine and Health Commons

How does access to this work benefit you? Let us know!

\section{Recommended Citation}

Jamshedji-Neogi, Armin, Renu Kapoor, Jayashree Kumar, Ashwini Bhalerao Gandhi, Lakshmi Murthy, K.G. Santhya, Shireen J. Jejeebhoy, Saswata Ghosh, Vijaya Nidadavolu, Nicole Haberland, Komal Saxena, and M.A. Jose. 2007. "Towards messages that matter: Understanding and addressing HIV and SRH risks among married young people in India," Research update. New Delhi: Population Council. 


\section{Authors}

Armin Jamshedji-Neogi, Renu Kapoor, Jayashree Kumar, Ashwini Bhalerao Gandhi, Lakshmi Murthy, K.G. Santhya, Shireen J. Jejeebhoy, Saswata Ghosh, Vijaya Nidadavolu, Nicole Haberland, Komal Saxena, and M.A. Jose 

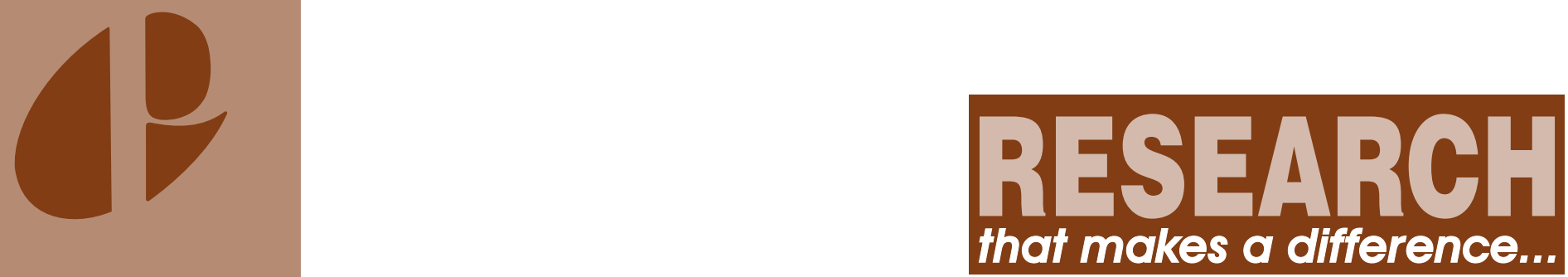

\section{TOWARDS MESSAGES THAT MATTER: Understanding and addressing HIV and SRH risks among married young people in India}

\section{Background}

Although there is growing programme interest in young people's SRH situation and needs in India, married young people have received little attention as a vulnerable group with distinct needs because marriage is assumed to be safe and because married youth are assumed to face none of the stigma that their unmarried counterparts experience in accessing SRH services. However, the emerging evidence shows that within the subpopulation of young people, married young women and men constitute groups with distinct risks of HIV and other poor SRH outcomes. There remains a huge need to better understand their needs and unique vulnerabilities, and to design programmes that take account of their special circumstances. In response to this need, the Population Council and the Family Planning Association of India undertook a large research project intended to better understand the situation and vulnerabilities faced by married young women and men and factors underlying these, and to develop communication materials for married young women and men and training materials for providers to address HIV and other sexual and reproductive health (SRH) risks experienced by these major youth sub-populations.

\section{Description of project}

The study was conducted in rural settings in Guntur district of Andhra Pradesh, characterised by low median age at marriage and first birth, and high levels of STI/HIV and in Dhar and Guna districts of Madhya Pradesh, characterised by early median age at marriage and first birth, and low levels of STI/HIV. These two contrasting settings were selected to explore the extent to which the perceptions of different stakeholders about married young people's SRH vulnerability, including STI/HIV vulnerability, their experiences in delivering services to married youth and above all, married young people's ability to adopt protective behaviours, differ in settings at different stages of the HIV epidemic even while such structural factors as marriage age are similar. The project comprised several components as described below.

Review of existing national and state-level policies and programmes: A review of existing national and state-level policies and programmes intended to reduce HIV vulnerability and improve SRH among young people in India was undertaken to identify the extent to which these policies and programmes have addressed the gamut of unique sexual and reproductive needs of young women and men. Taking the example of two states, namely, Andhra Pradesh, characterised by both early marriage and high HIV prevalence, and Madhya Pradesh, characterised by early marriage and low rates of HIV, the review also explored the extent to which programmes have been adapted to accommodate state-level differences in the sexual and reproductive vulnerability of youth. The review focused on four programme dimensions, namely, awareness building, service provision, reducing gender disparities and developing a supportive environment.

Study of stakeholders from the health and nonhealth sectors: A small-scale study was conducted among stakeholders from the health and non-health sectors to assess their interaction with young people, their perceptions about the vulnerability of young people and the factors that facilitate or hinder their capacity to provide SRH information and services to young people. Respondents from the health sector included all categories of providers at sub-centre, primary health centre and community health centre levels as well as village health volunteers if available. Participants from other sectors included representatives from the Integrated Child Development Services, teachers from high 
schools, representatives of women's and youth groups, representatives of non-governmental organizations and representatives of panchayats. A brief structured questionnaire was administered to all respondents. A total of 599 stakeholders were contacted; 93 percent were successfully interviewed. In addition, a total of 8 in-depth interviews with medical officers and 12 focus group discussions with auxiliary-nursemidwives were conducted. Findings suggest that while stakeholders are a valuable resource to address young people's needs, their abilities are limited by such factors as discomfort about addressing sensitive sexual and reproductive matters, lack of appropriate training and a paucity of relevant informational materials.

Study of married young women and men: A cross-sectional study, comprising of a pre-survey qualitative phase and a survey, was conducted among married young women aged 15-24 years and men aged $15-29$ years in 27 villages in Guntur district and 42 villages each in Dhar and Guna districts to better understand the situation and special vulnerabilities of married young women and men in relation to HIV and other sexual and reproductive matters. In the pre-survey qualitative phase, focus group discussions were conducted to explore general perceptions about married young people's vulnerability to HIV/AIDS and other poor SRH outcomes; their ability to exercise informed sexual and reproductive choices; and their views about existing BCC materials and strategies best suited for conveying messages about actions that could protect them against such risks.

The survey gathered information on married young women's and men's sexual experiences both before and within marriage, their ability to adopt protective strategies including reducing the number of sexual partners, use of condoms for dual protection, voluntary testing for HIV, notification of partners and prompt treatment of sexually transmitted infections (STIs), delaying the first pregnancy, and adopting healthy pregnancy-related practices and seeking timely care during pregnancy and the postpartum period. It also collected information on factors underlying their ability to adopt protective actions including awareness of safe practices, selfperceptions of risk, access to appropriate services and sensitive providers, and gender role and power factors. A total of 1370 young women and 1075 young men in Guntur, 1717 young women and 1547 young men in Dhar and Guna were interviewed in the survey. Study findings highlight the fact that significant minorities of married young women and men have experienced unsafe pre-marital and in some cases extramarital sexual relations, self-perceptions of risk of acquiring sexually transmitted infections are unrealistic and access to care for sexual and reproductive health care including pregnancyand infection-related care is limited.

Designing communication materials for married young people: With inputs from the formative research, communication materials, trainers' modules and take-aways for young people, have been designed. Key messages were tailored to the special needs of both literate and semi-literate married young people in rural settings and focussed on four thematic areas, namely, family planning, pregnancy-related care, safe abortion and STI/HIV issues. These materials attempt to enable married youth to question factors that undermine their ability to delay first pregnancy; to introspect on personal vulnerability to STIs/HIV; sensitize them about the risk associated with childbearing at young ages and importance of seeking proper and timely care during pregnancy, childbirth and the postpartum period; and inform them about the risk of late trimester abortions and importance of seeking abortion services from qualified providers. They also attempt to dispel myths and misconceptions around these topics.

Designing training modules for health care providers: A training module to sensitize health care providers to the unique needs and vulnerabilities of married adolescents and youth have also been drafted. The module is intended to supplement the comprehensive strategy outlined in the Implementation Guide on RCHII for state and district programme managers (MOHFW 2006) and the Orientation Programme for ANMs/LHVs to provide Adolescent-friendly Reproductive and Sexual Health Services (MOHFW 2006). It attempts to orient health care providers about: why married young people are important and different; how to effectively communicate with married adolescents and young women as well as men; and how to make existing services friendly for married young people.
1) Population Council

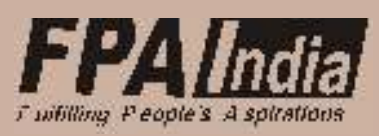

For further information please contact:

Population Council

Zone 5A, Ground Floor

India Habitat Centre, Lodi Road

New Delhi - 110 003, India

Tel: 91-11-2464 2901/02

Fax: 91-11-2464 2903

Email: info-india@popcouncil.org

\section{wWw.popcouncil.org}

\section{Contributors}

Armin Jamshedji-Neogi, Renu Kapoor, Jayashree Kumar (Family Planning Association of India); Ashwini Bhalerao Gandhi (Independent Consultant); Lakshmi Murthy (Vikalp Design); KG Santhya, Shireen Jejeebhoy, Saswata Ghosh, Vijaya Nidadavolu, Nicole Haberland, Komal Saxena, MA Jose (Population Council).

Donor

Department for International Development, UK 